\title{
Perancangan Jaringan dan Manajemen Bandwidth User dengan Mikrotik di Dinas Kominfo Provinsi Sumatera Utara
}

\author{
Network Design and Management of User Bandwidth with Microtik in Communication \\ and Informatics Office of North Sumatra Province
}

\author{
Dedi Sanjaya Tampubolon ${ }^{1}$, Hanifah Aprilyani ${ }^{2}$, Ridho Wahyudi Pulungan ${ }^{3}$ \\ ${ }^{1,2,3}$ Fakultas Sains dan Teknologi, Universitas Islam Negeri Sumatera Utara \\ E-mail: ${ }^{1}$ Dedisanjaya27@icloud.com, ${ }^{2}$ Hanyfah.Aprlyn24@gmail.com, \\ ${ }^{3}$ Ridhopulungan26@gmail.com
}

\begin{abstract}
Abstrak
Jaringan komputer adalah sekelompok komputer yang menggunakan protokol komunikasi untuk berkomunikasi satu sama lain dan bertukar data atau informasi. Internet juga dapat diartikan sebagai jaringan komputer dalam arti luas. Kebutuhan akses internet pengguna atau user sangat tinggi dan kinerja sistem menurun saat mengirim data karena kondisi internet yang tidak stabil. Oleh karena itu, sangatlah penting mengatur dan membatasi penggunaan bandwidth pada internet yang memiliki koneksi terbatas. Kita perlu membatasi bandwidth untuk setiap pengguna yang terhubung ke router mikrotik. Router mikrotik sendiri memiliki kemampuan untuk membatasi bandwidth yaitu dengan fitur queue. Dengan menggunakan metode simple queue dan queue tree, kita dapat merancang batasan bandwidth yang membuat koneksi Internet di perusahaan atau instansi lebih stabil sehingga setiap user atau pengguna yang menggunakan internet mendapatkan akses yang cukup dengan kebutuhan yang diperlukan.
\end{abstract}

Kata kunci: Bandwidth, Mikrotik, Simple Quеие, Quеuе Tree

\begin{abstract}
A computer network is a group of computers that use communication protocols to communicate with each other and share data or information. The internet can also be interpreted as a computer network in a broader sense. The need for internet access is very high for users, making slow system performance to send data due to unstable internet conditions. Therefore, in regulating and limiting the use of internet bandwidth, it is indeed an important thing when the internet connection is limited, for example, the limited bandwidth quota from the ISP. We need to limit the bandwidth quota for each user connected to the mikrotik router. On the mikrotik router itself, there are features that can limit (limit) bandwidth, namely queue. By using the simple queue and queue tree methods, you candesigning bandwidth restrictions that make internet conditions in a company can be maintained and more stable due to bandwidth restrictions for each user who use the internet.
\end{abstract}

Keywords: Bandwidth, Microtik, Simple Queue, Queue Tree

\section{PENDAHULUAN}

Jaringan komputer adalah sekelompok komputer yang menggunakan protokol komunikasi untuk berkomunikasi satu sama lain dan bertukar data atau informasi. Internet juga dapat diartikan sebagai jaringan komputer dalam arti luas. Internet telah menciptakan berbagai peluang baik di bidang pendidikan, komunikasi, keuangan dan pemerintahan. Untuk meningkatkan produktivitas tenaga kerja kita dapat melakukan dengan memaksimalkan penggunaan jaringan pada komputer. Ini adalah faktor bahwa banyak perusahaan dan instansi 
pemerintah terus meningkatkan kinerja jaringan komputer mereka. Jaringan komputer pada suatu instansi menawarkan banyak manfaat, termasuk transfer data yang cepat dan efisien serta akses untuk mengunduh dan mengunggah file, sehingga menghemat pemakaian. Internet dapat membuat segalanya lebih mudah, tetapi salah satu hambatan yang perlu diingat adalah terbatasnya bandwidth internet yang tersedia di perusahaan ataupun instansi. Adapula resiko yang sering terjadi seperti kesalahan pada jaringan ataupun kehilangan data saat terjadinya lag dalam penggunaan jaringan. Maka dari itu karena banyaknya pengguna di kantor dinas Kominfo Provinsi Sumatera Utara, mengharuskan membuat batasan pengguna agar tidak terjadinya lag pada server utama.

\section{METODE PENELITIAN}

\subsection{Alur Sistem Metode Simple Queue dan Queue Tree Menggunakan HTB (Hierarchical Token Bucket)}

Dalam manajemen bandwidth terdapat 2 sistem metode yang digunakan, yaitu simple quеие dan quеие tree. Sebelum melanjutkan ke pengujian penulis akan menjelaskan terlebih dahulu flowchat untuk Simple Queue dan Queue Tree.

\section{Flowchart Simple Queue}

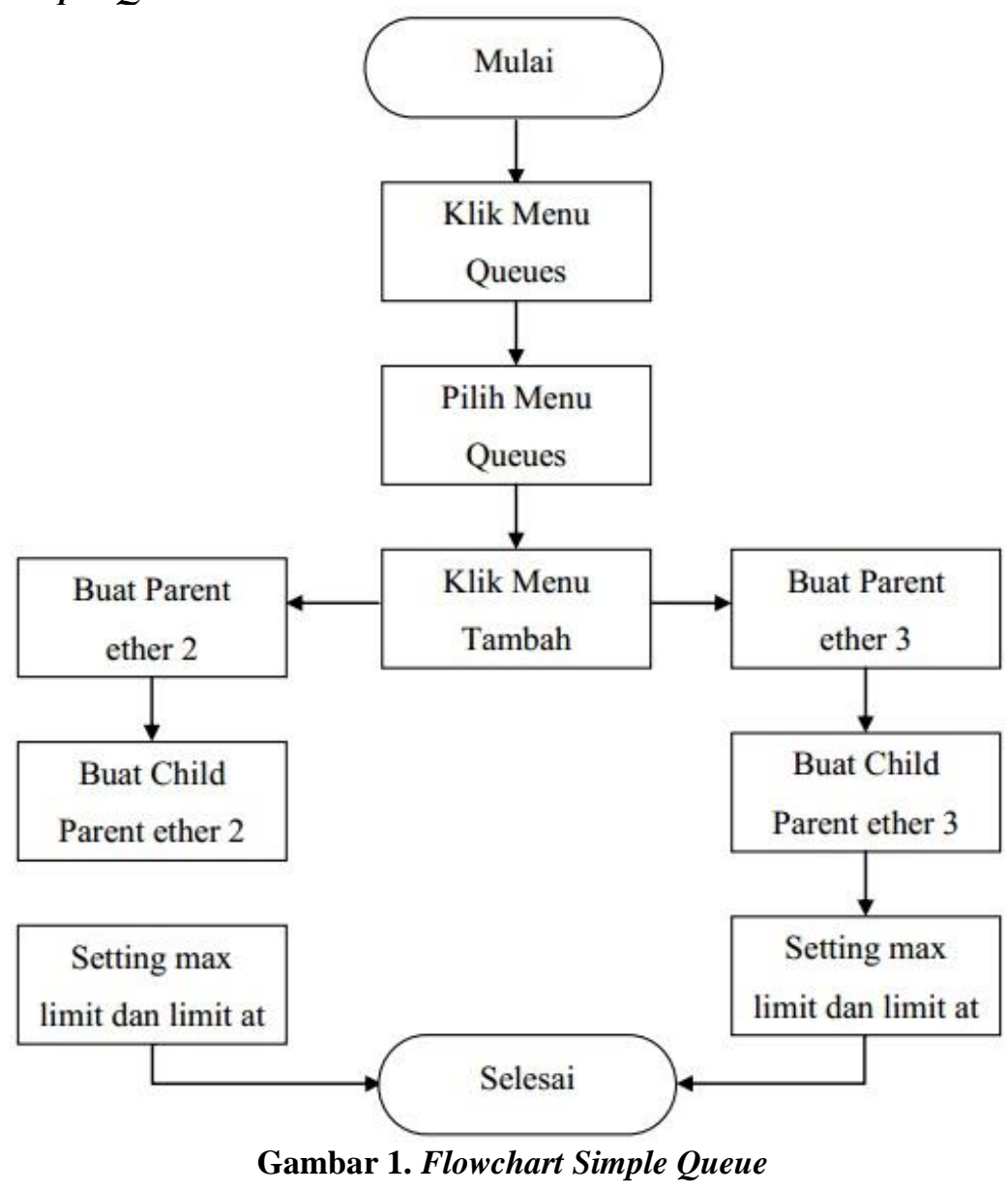

Flowchart Queue Tree 


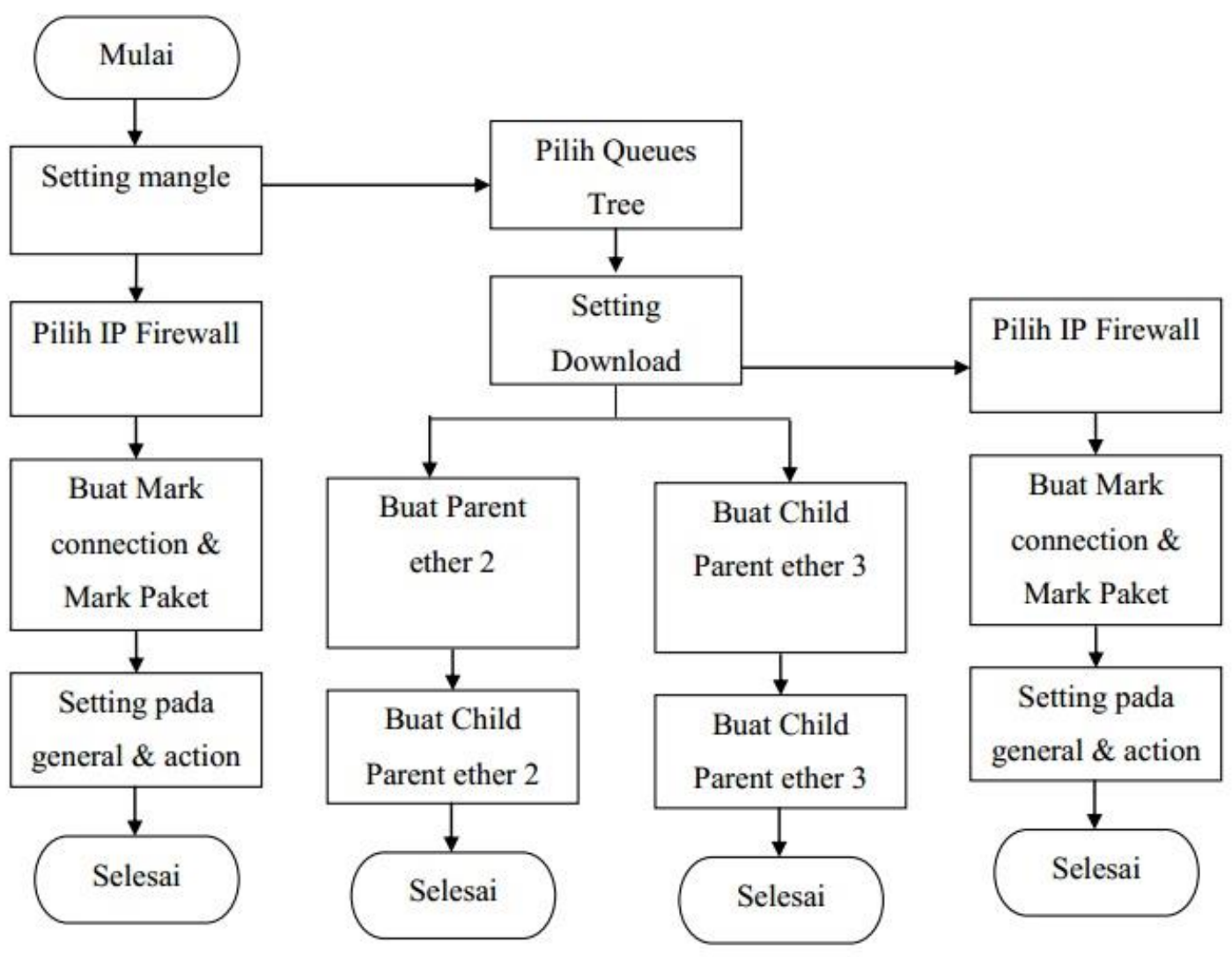

Gambar 2. Flowchart Queue Tree

\subsection{Deskripsi Detail Alur Sistem Metode Simple Queue \& Queue Tree Menggunakan HTB} (Hierarchical Token Bucket)

Metode Simple Queue

Dalam flowchart sistem metode Simple Queue diatas dapat dijelaskan konfigurasinya sebagai berikut ini:

- Langkah awal membuka menu Queues.

- Kemudian pilih Simple Queues.

- Klik menu Tambah (+) .

- Buat parent ether 2 dan ether 3.

- Masukkan ip-address sesuai ether yang telah di buat sebelumnya. Seperti gambar 1.

- Lalu masukkan max download dan max upload.

- Buat child parent ether 2 dan juga ether 3.

- Pada ether 2 masukkan IP PC biling dan ether 3 masukkan IP PC client. Seperti pada gambar 1.

- Setelah itu masukkan max limit dan limit at download maupun upload.

\section{Simple Queue}

Dalam flowchart sistem metode Queue Tree diatas terdapat beberapa perbedaan dengan setting simple queue, dapat dijelaskan konfigurasinya sebagai berikut :

- Diawali dengan setting mangle terlebih dahulu.

- Pilih IP selanjutnya pilih Firewall.

- Buat mark connection untuk ether 2 dan untuk ether 3 terlebih dahulu.

- Lalu buat mark packet untuk ether 2 dan untuk ether 3.

- Setelah itu setting pada menu General dan Action dan dilanjutkan dengan setting Queues Tree.

- Buat parent download untuk ether 2 dan juga ether $3 \rightarrow$ setting max limit. 
- Kemudian buat child parent download untuk ether 2 (IP PC Biling) maupun ether 3 (IP PC Client). Seperti pada gambar 2.

- Setelah itu setting juga bagian parent, max limit dan limit at.

- Dilanjutkan membuat bagian parent upload untuk ether $1 \rightarrow$ setting max limit.

- Buat child parent upload $\rightarrow$ setting IP Address. Seperti pada gambar 2.

- Dan yang terakhir setting parent, max limit dan juga limit at.

\section{HASIL DAN PEMBAHASAN}

\subsection{Pelaksanaan Sistem Yang Berjalan}

Sangatlah penting untuk mengatur dan membatasi pemakaian bandwidth internet, ketika koneksi internet terbatas seperti halnya juga kuota bandwidth yang terbatas dari ISP. Dengan begitu kita perlu membatasi kuota bandwidth tiap user atau pengguna yang terkoneksi pada router mikrotik. Dalam router mikrotik sudah tersedia sebuah fitur yang bisa membatasi (limit) bandwidth yaitu fitur Queue. Ada dua macam jenis Queue yaitu :

- Queue Simple : Metode ini merupakan cara termudah untuk melakukan manajemen limit bandwidth yang diterapkan pada sebuah jaringan skala kecil sampai dengan skala menengah yang bertujuan untuk mengatur pemakaian pada bandwidth upload maupun download di tiap user-nya.

- Queиe Tree : Metode queue tree ini juga sama seperti metode queue simple, akan tetapi cara yang diperoleh lebih rumit karena pada metode ini dapat melakukan pembatasan bandwidth berdasarkan grup bahkan secara hierarki. Setelah itu kita harus mengaktifkan terlebih dahulu fitur Mangle pada Firewall jika ingin menggunakan metode ini.

\subsection{Analisis Sistem Yang Berjalan}

Rancangan Pengujian QOS (Quality Of Service) Sistem Metode Simple Queue dan Metode Queue Tree Menggunakan HTB (Hierarchical Token Bucket)

Pengujian pada manajemen bandwidth juga di lakukan dengan cara membandingkan hasil QoS (Quality Of Service) antara simple queue dengan queue tree. Pada penelitian ini, bandwidth total yang dimiliki oleh kantor dinas kominfo provinsi sumatera utara adalah 10Mbps untuk Download dan 1Mbps untuk Upload. Jumlah client yang tersambung ada 6 client. Dalam hal ini penulis dapat membatasi setiap client-nya agar mempunyai maksimal download 2Mbps dan maksimal Upload 512Kbps agar semua client mendapatkan kuota bandwidth yang telah di atur.

\section{Simple Queue}

Berikut ini ialah langkah-langkah konfigurasi manajemen bandwidth dengan metode Simple Queue :

1. Pilih menu Queues $\rightarrow$ Simple Queues $\rightarrow$ klik tambah (+). 


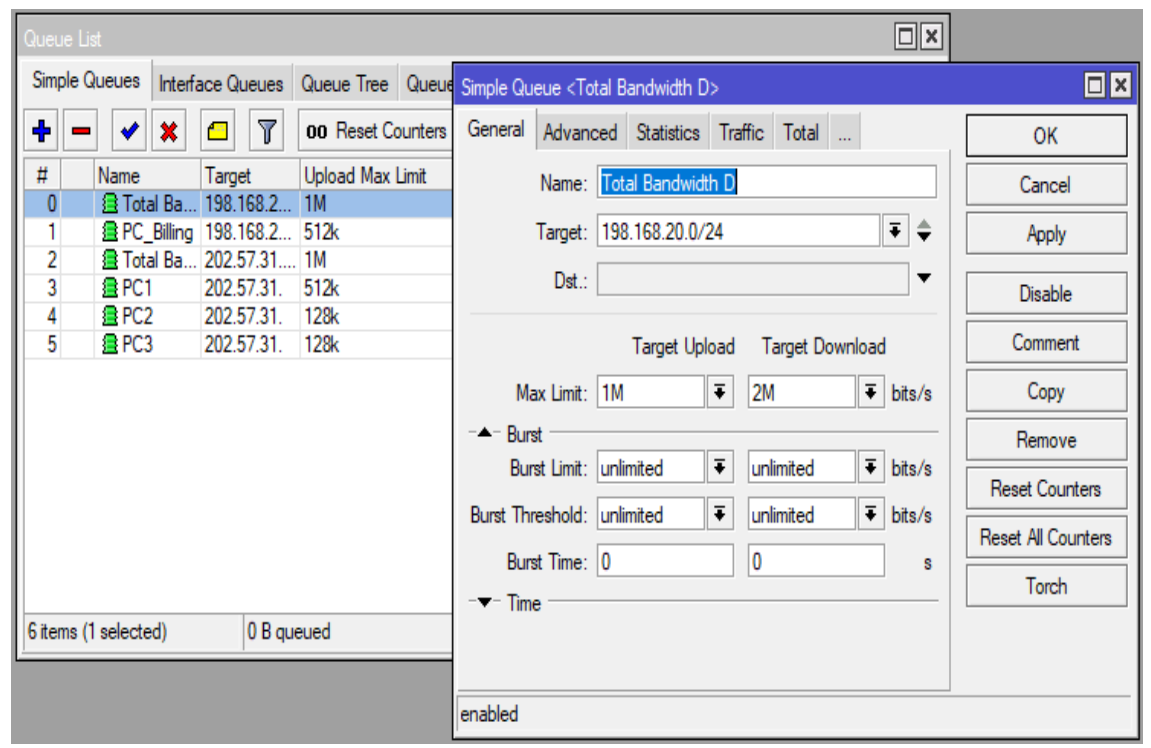

\section{Gambar 3. Total Bandwidth D}

Pada perangkat Router tersebut, kita tidak mengetahui berapa total bandwidth $D$ real yang ada, maka dari itu kita harus definisikan pada langkah pertama. Pendefinisian juga bisa dilakukan dengan melakukan setting pada queue parent. Besar pada bandwidth yang telah kita miliki tentu bisa diisi dengan parameter Target Upload Max-Limit atapun

\section{Target Download Max-Limit.}

Pada langkah berikutnya kita akan menentukan jumlah pembatasan per-client dengan melakukan setting child-queue. Pada child-queue kita dapat menentukan targetaddress dengan mengisikan IP address pada tiap masing-masing client-nya. Kita dapat menerapkan Limit-at (CIR) : 1 mbps dan Max-Limit (MIR) : 2 mbps. Arahkan ke Parent Total Bandwidth yang kita buat sebelumnya. Tahap berikutnya ulangi langkah sebelumnya untuk bisa memberikan limit pada client yang lain, sesuaikan TargetAddress.

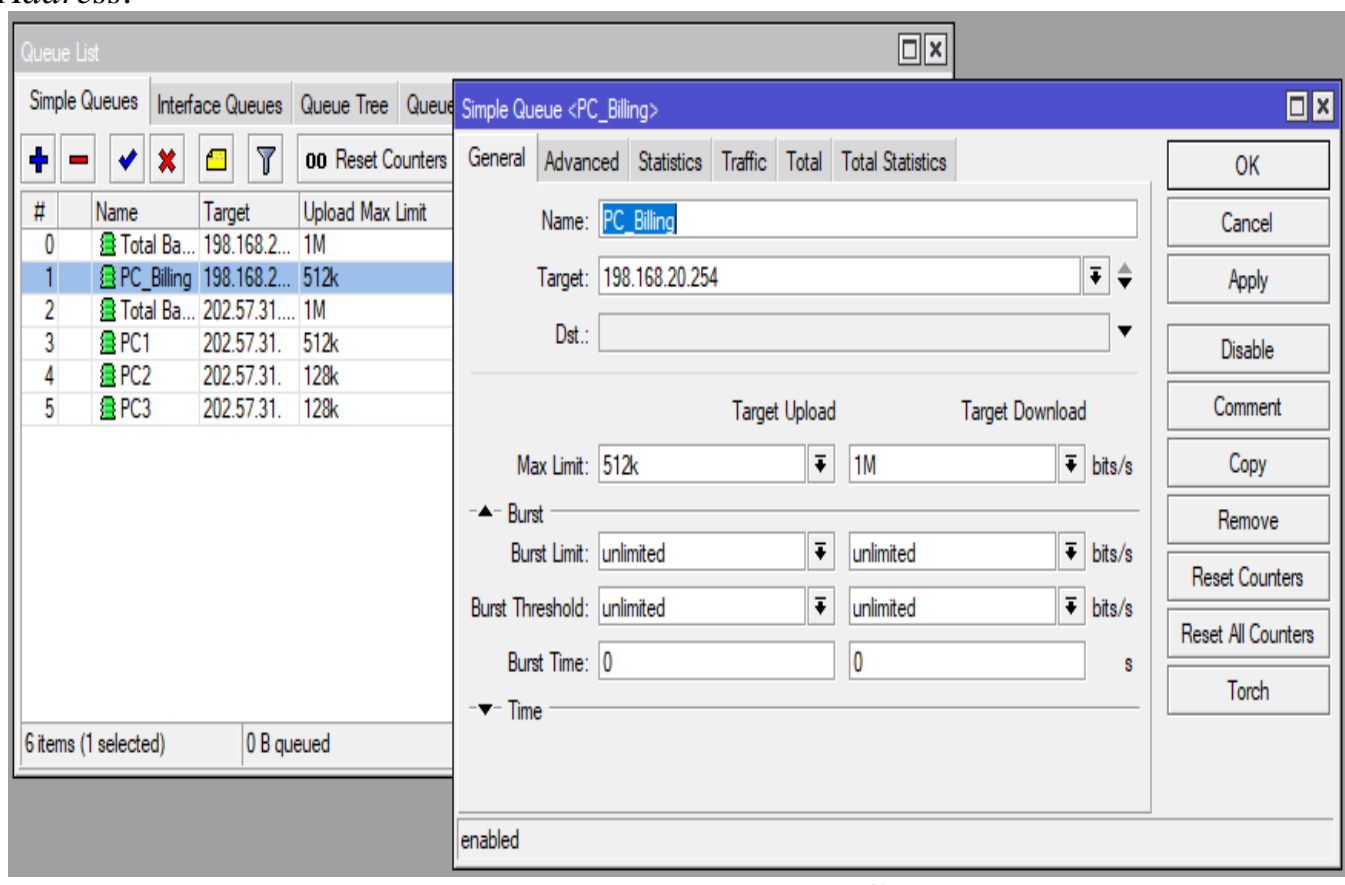

Gambar 4. Konfigurasi PC Billing

Selanjutnya kita dapat melakukan konfigurasi ip address untuk pc billing pada router mikrotik, klik ip-address kemudian klik tambah, lalu kita perkirakan bahwa ip 
address yang akan dipakai untuk pc billing yaitu 198.168.20.254, maka untuk konfigurasinya seperti gambar yang di atas. Dan terapkan Max-Limit (CIR) target upload : 512 kbps dan Max-Limit (MIR) target download : 1 mbps. Arahkan ke pc billing yang kita buat sebelumnya. Dengan ini kita dapat mengetahui berapa kecepatan sesuai TargetAddress yang telah ditentukan, jika sudah klik tombol "OK".

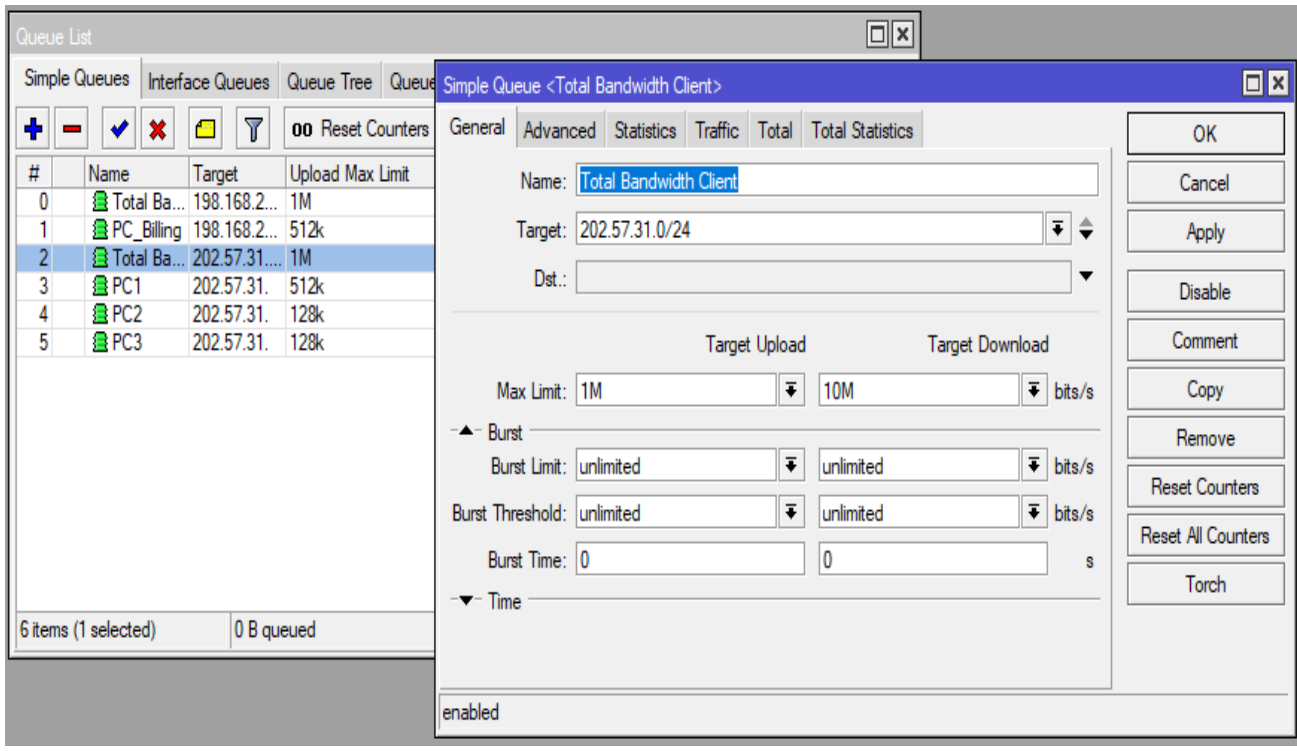

Gambar 5. Konfigurasi Bandwidth Client

Setelah itu kita akan melakukan konfigurasi Bandwidth Client, lalu kita akan menambahkan ip address sesuai dengan target yang ingin ditentukan pada bandwidthnya, dengan target 202.57.31.0/24. Di bagian Max Limit ini kita akan mentukan berapa batas kecepatan di sini dengan menggunakan target upload $1 \mathrm{M}$ dan juga target download 10 M. Lalu klik "OK”.

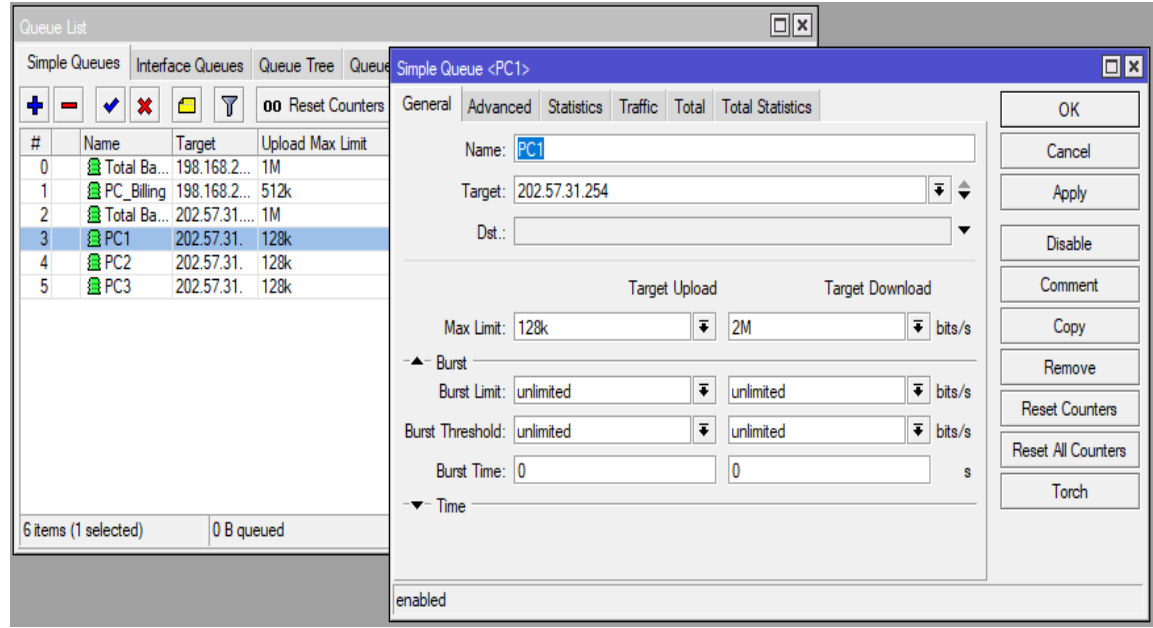

Gambar 6. Konfigurasi Parent PC 1

Pada tahap ini kita membuat child 1 yang artinya PC 1 dari Simple Queue pastikan terhubung ke Router Mikrotik. Lalu kita akan menambahkan ip address yang sudah di atur dengan target 202.57.31.254.

Kemudian kita akan menerapkan Max-Limit (CIR) target upload : 128 kbps dan Max- Limit (MIR) target download : 2M. Arahkan ke PC1 yang kita buat sebelumnya. Dengan ini kita bisa mengetahui seberapa jumlah kecepatan sesuai Target-Address, jika sudah dilakukan klik tombol "OK".

\section{Queue Tree}


Berikut langkah -langkah konfigurasi manajemen bandwidth menggunakan queue tree. Sebelum melanjutkan konfigurasi pada Queue Tree kita harus mengkonfigurasi dahulu mangle-nya, fungsi dari konfigurasi itu ialah untuk menandai koneksi maupun paket yang masuk pada server mikrotik.

2. Pilih IP $\rightarrow$ Firewall $\rightarrow$ Mangle

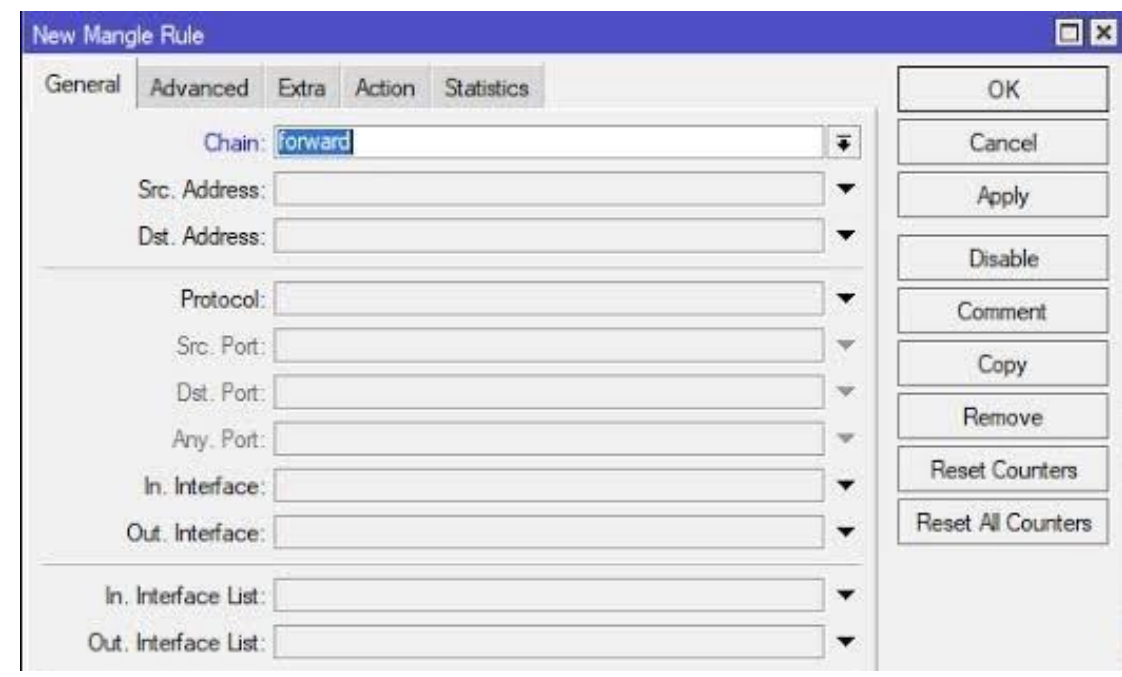

Gambar 7. Mangle Rule

Ada sebuah fitur yang terdapat pada Router OS MikroTik disebut dengan "Firewall". Fitur firewall ini juga banyak digunakan untuk melakukan filtering akses (Filter Rule), Forwarding (NAT), dan juga untuk menandai koneksi maupun paket dari trafik data yang melewati router (Mangle).

Agar fungsi dari fitur firewall ini dapat berjalan dengan baik, kita juga harus menambahkan dan menentukan rule-rule yang sesuai. Terdapat sebuah parameter utama pada rule di fitur firewall yaitu 'Chain'. Parameter chain memiliki kegunaan untuk menetukan jenis trafik yang akan di-manage pada fitur firewall dan setiap fungsi pada firewall seperti Filter Rule, NAT, Mangle memiliki opsi chain yang berbeda.

Forward :

Forward juga digunakan untuk memproses trafik paket data yang hanya melewati router. Contohnya seperti trafik dari jaringan public ke local maupun sebaliknya dari jaringan local ke public, contoh seperti kasus yang sering terjadi adalah seperti pada saat kita melakukan browsing. Trafik pada laptop browsing ke internet dapat di-manage oleh firewall dengan menggunakan chain forward. 


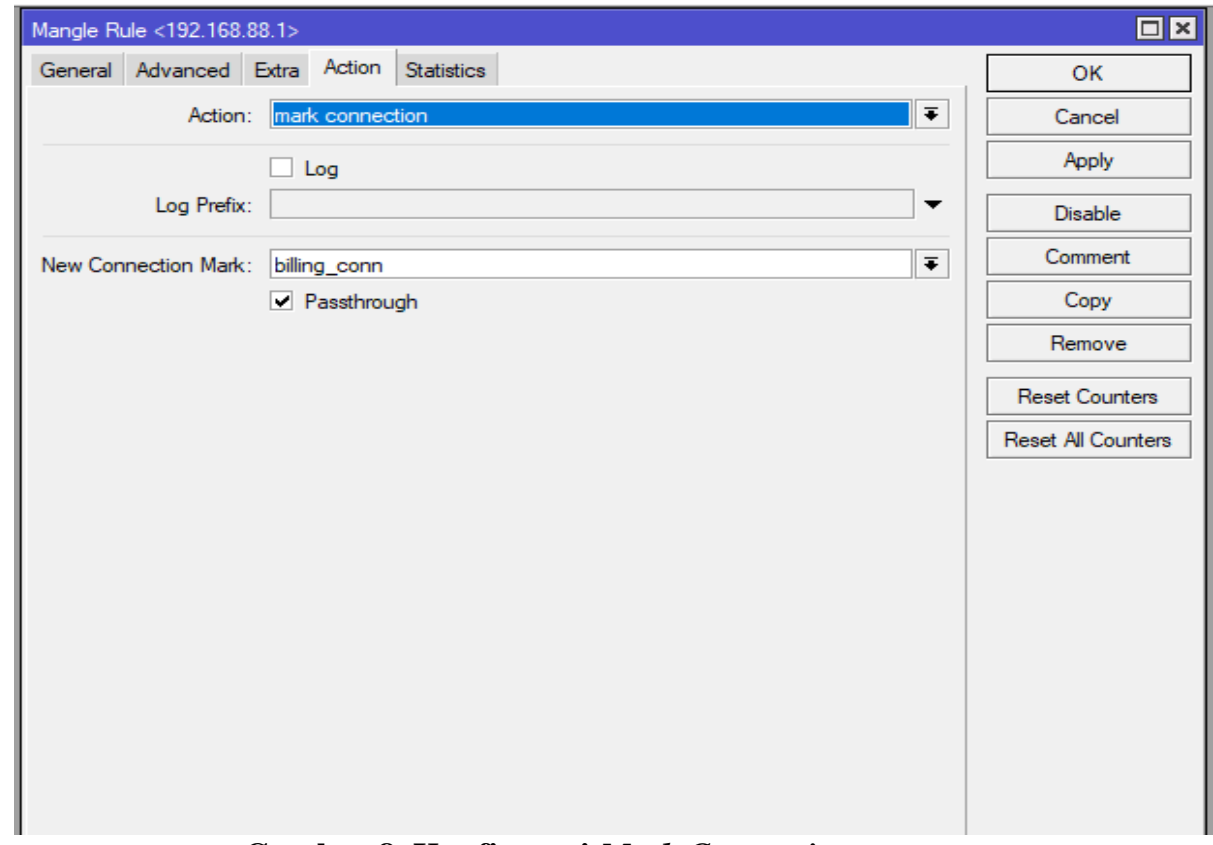

Gambar 8. Konfigurasi Mark Connection

Setelah itu kita dapat pindah pada tab action dan memasukan action $=$ mark connection $\rightarrow$ new connection mark $=$ connect-ip-pc $\rightarrow$ ceklis pada tulisan passthrough $\rightarrow$ lalu apply dan ok

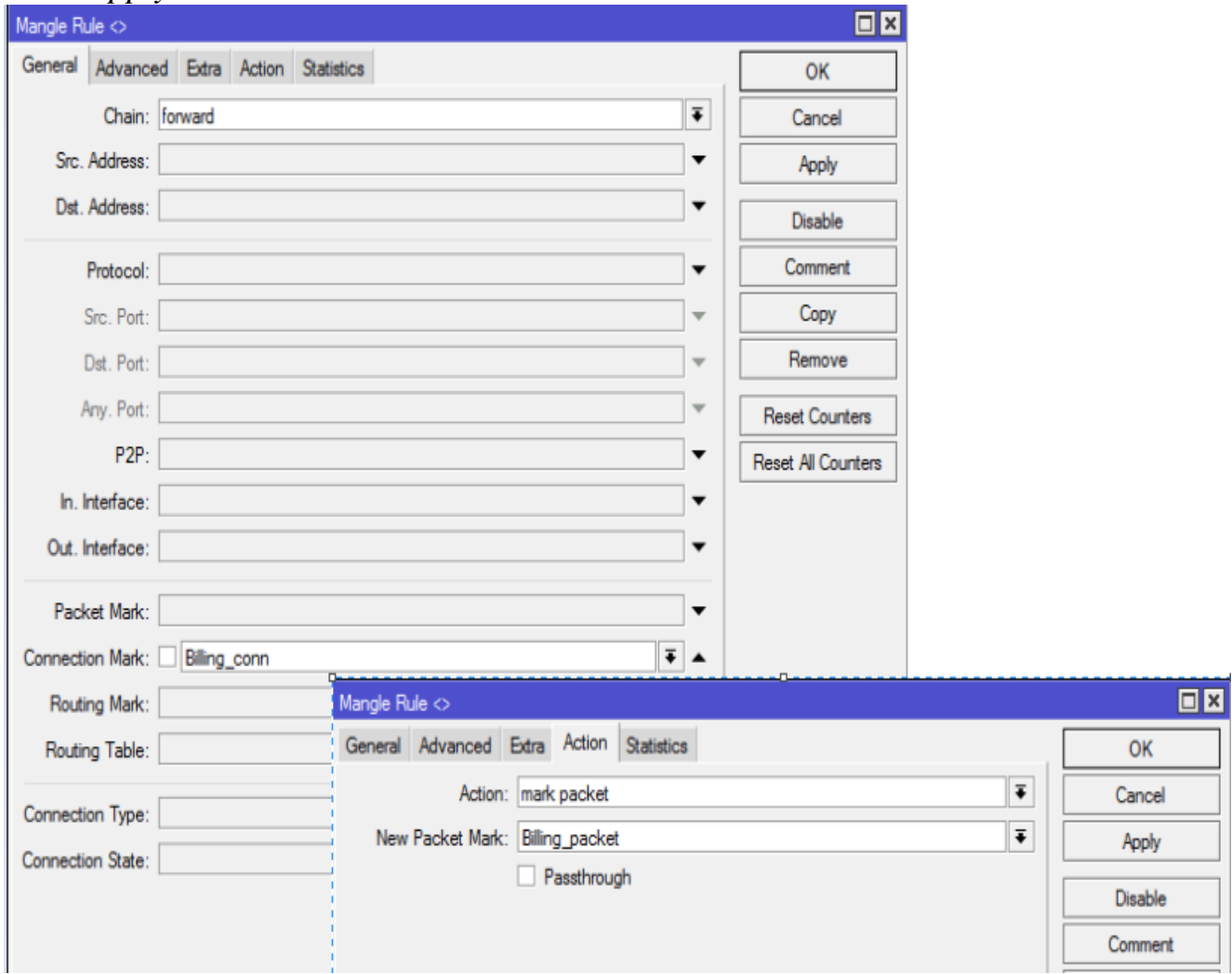

\section{Gambar 9. Konfigurasi Mark Packet}

Kemudian membuat mangle yang terakhir $\rightarrow$ add $\rightarrow$ pada tab general isi chain $=$ Forward $\rightarrow$ connection mark $=$ Billing_conn . Selanjutnya kita pindah pada tab action dan masukkan action $=$ mark packet $\rightarrow$ new packet mark $=$ Billing_packet $\rightarrow$ tidak perlu di ceklis pada tulisan passthrough $\rightarrow$ lalu apply dan ok. 
1. Lakukan pengulangan konfigurasi mark connection dan mark packet sampai semua client terpenuhi.

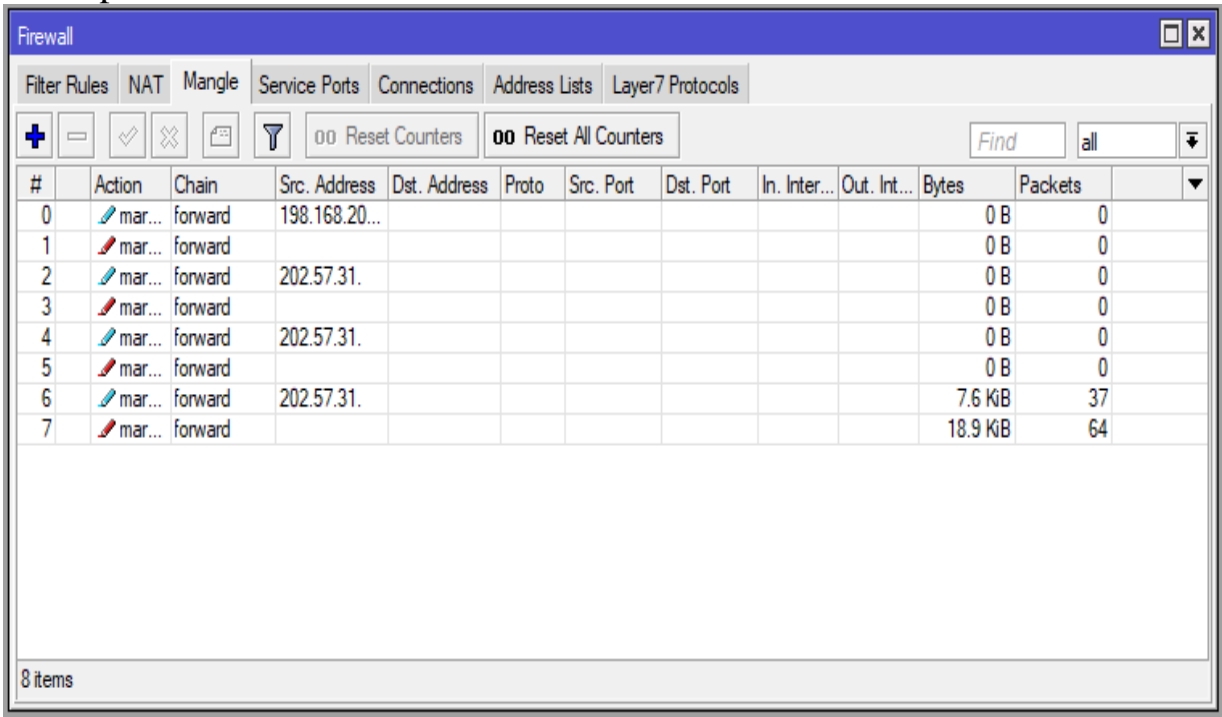

\section{Gambar 10. Mangle List}

Berikut adalah hasil dari data pengulangan baik dari mark connection maupun mark packet sehingga client bisa mendapatkan masing-masing scr Address dengan IP yang perbeda dengan itu byte-nya menyesuaikan.

2. Pilih тепи Quеиеs $\rightarrow$ Quеие Tree $\rightarrow$ klik tambah (+).

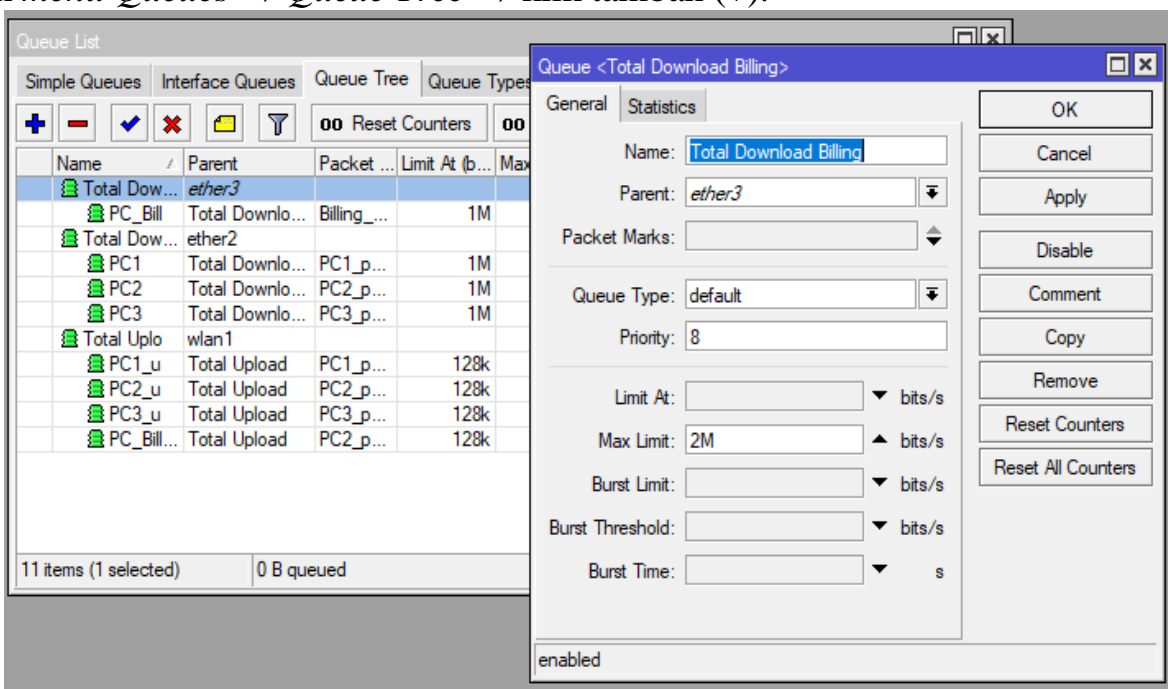

\section{Gambar 11. Total Download Billing}

Isi kolom Name : Total Download Billing $\rightarrow$ Parent $;$ ether $3 \rightarrow$ Max Limit (Sesuai Bandwith yang ada atau yang dikehendaki) kita menggunakan $2 \mathrm{M} \rightarrow$ Klik OK.

3. Dalam membuat parent dan child parent download, pilih menu lalu Queues $\rightarrow$ Queues Tree. 


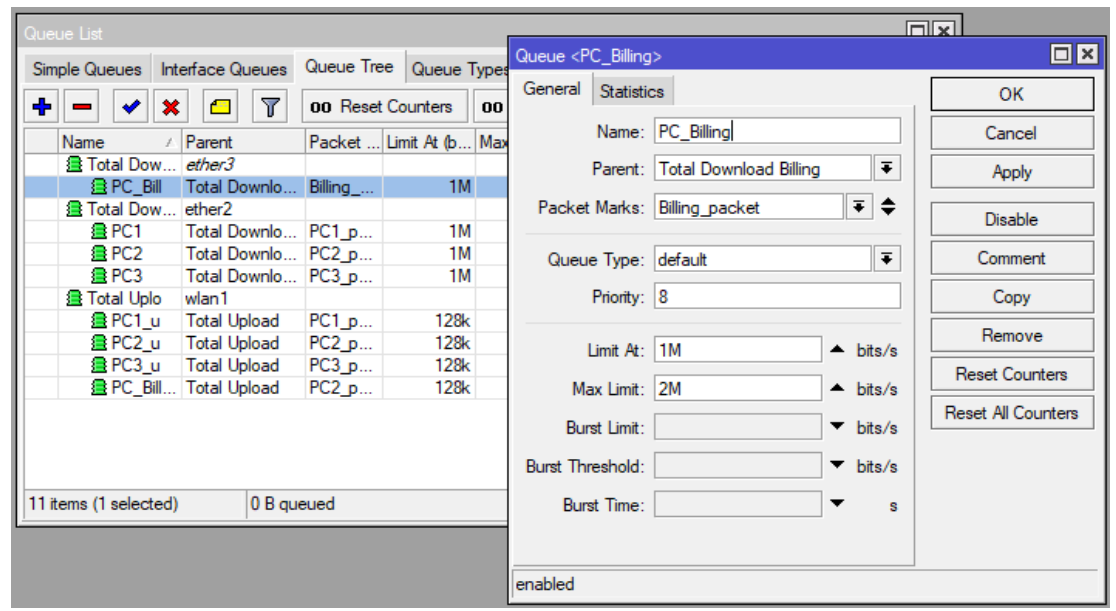

Gambar 12. Konfigurasi Parent Download PC Billing

Pilih menu Queues $\rightarrow$ Queue Tree $\rightarrow$ klik tanda "+" $\rightarrow$ Isi kolom Name $:$ PC Billing (sesuaikan) $\rightarrow$ Parent ; Total Download Billing $\rightarrow$ Max Limit (Sesuai Bandwith yang ada atau yang dikehendaki) $\rightarrow$ Klik OK.

4. Langkah selanjutnya sama dengan induk queue, namun untuk child queue lebih dispesifikkan sesuai dengan rule mangle dan $P C Q$ yang telah dibuat sebelumnya.

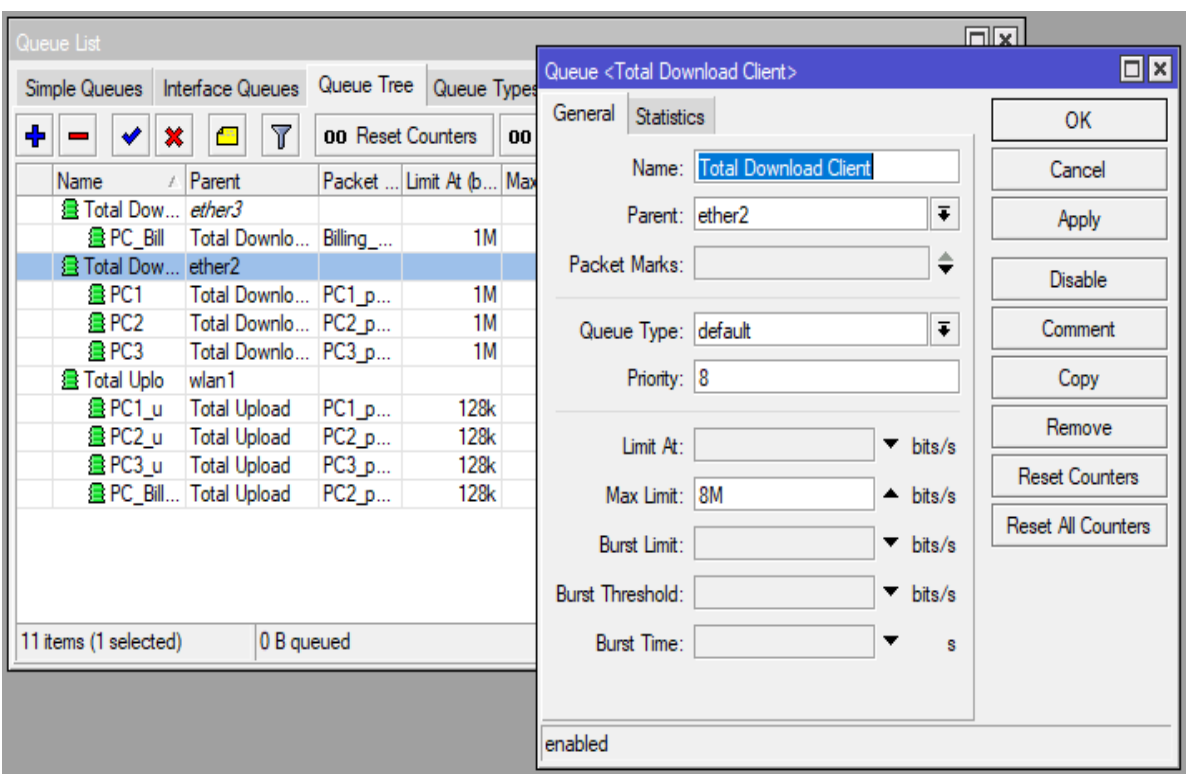

Gambar 13. Konfigurasi Download PC Client

Setelah selesai membuat queиe tree untuk parent, kita akan membuat queue tree untuk client/host. Beberapa parameter yang akan kita gunakan dalam membuat queue tree untuk client adalah :

1. Name : Total Download Client

2. Parent : ether 2

3. Download (pilih parent download yang sebelumnya dibuat

4. Max-limit : $8 \mathrm{M}$

5. Lalu klik OK 


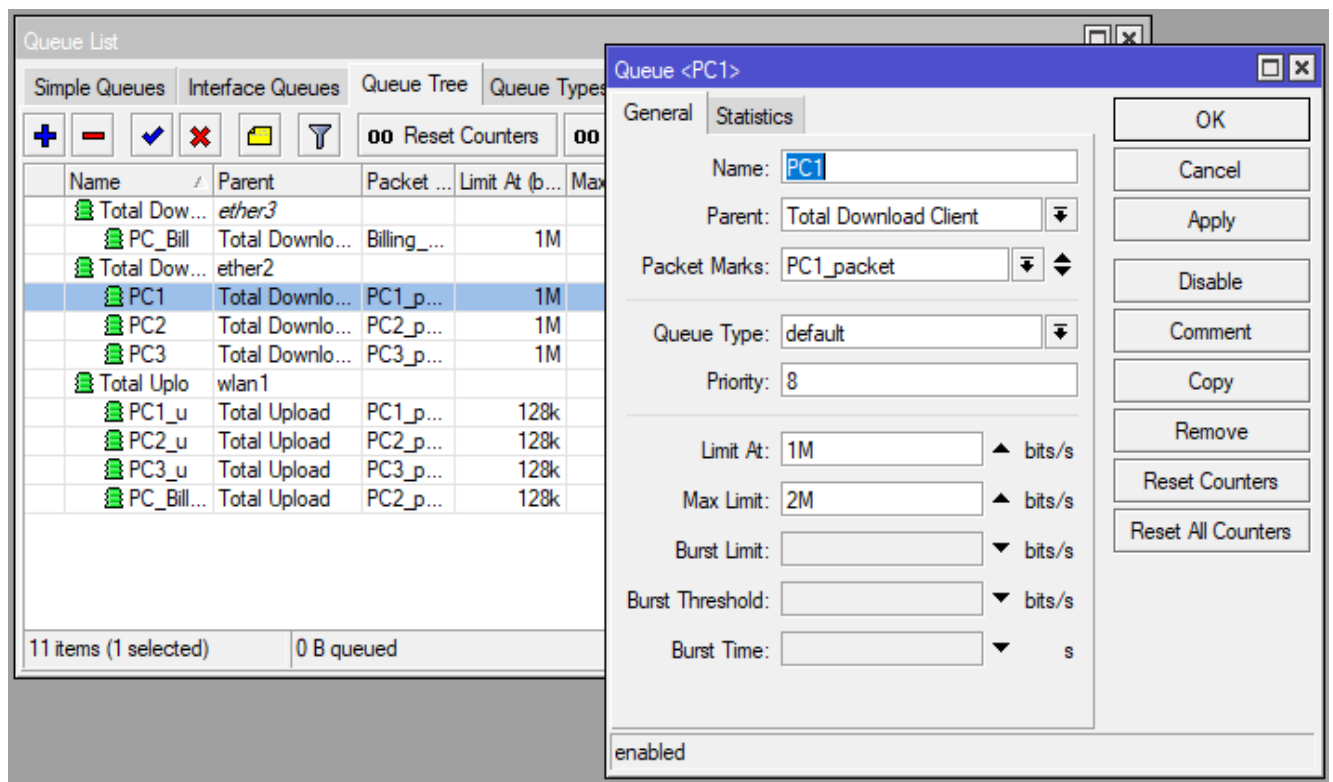

Gambar 14. Konfigurasi Child Parent PC Client

Selanjutnya kita akan membuat $p c$ client pada child parent yang dimana kita bisa menentukan namanya terlebih dahulu di antaranya ada beberapa pamarameter yang berhubung menggunakan $1 \mathrm{PC}$, maka dari itu kita akan memberi nama PC1. Kemudian untuk perent kita akan mengisi Total download Client, lalu pada packet mark kita mengisi PC1_packet untuk mengetahui apakah terdeteksi PC 1 yang kita buat.

Setelah itu kita menyeting Limit-at kecepatan minimum yang dapat diberikan kepada client kita menggunakan $1 \mathrm{M}$ dan Max-limit : kecepatan maksimum yang didapat client kita menggunakan 2M. lalu tekan OK.

Dengan ini kita dapat mengetahui saat kita men-download file dan saat mengupload file antara server ke client melalui PC yang sudah di setting. Dan untuk mengetahui perbedaan total download dengan total upload bisa menggunakan speed

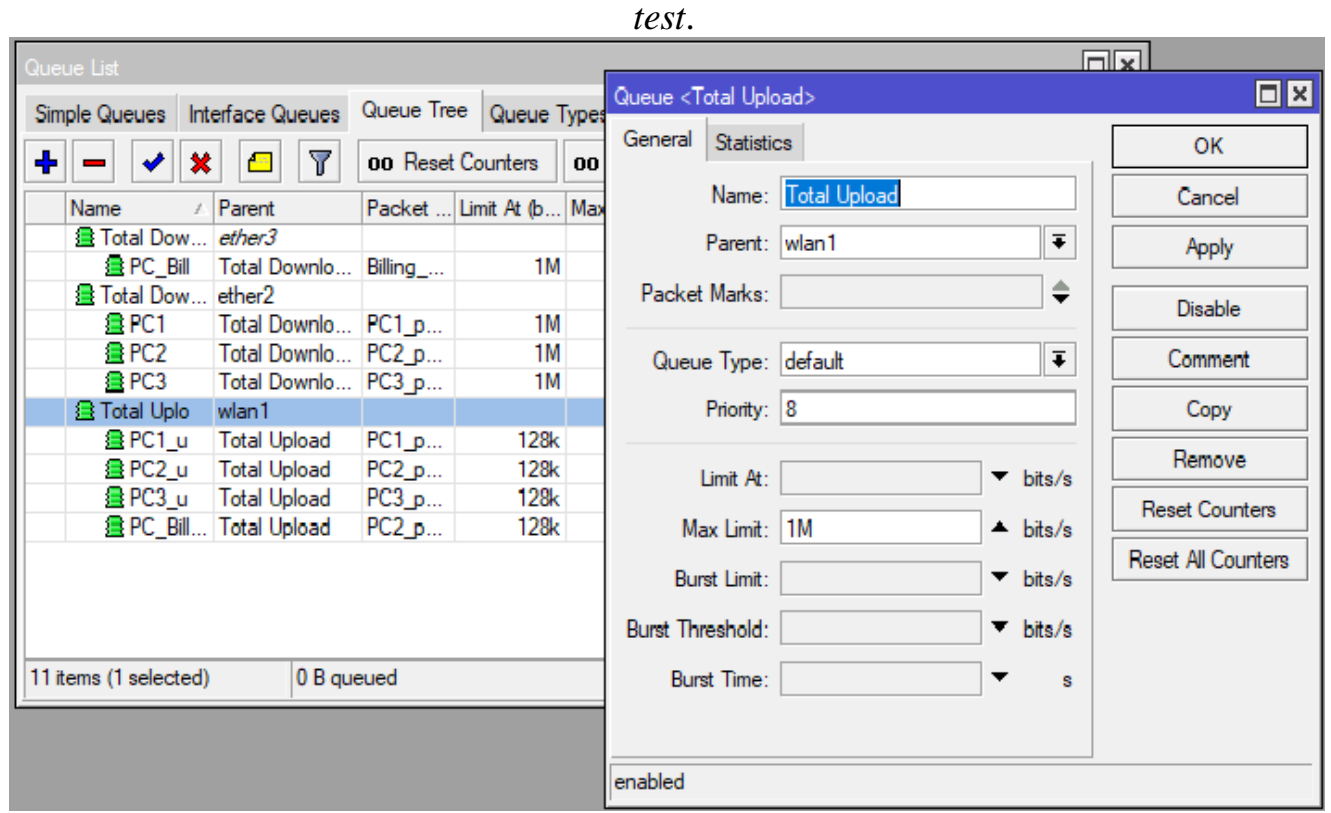

Gambar 15. Konfigurasi Parent Download PC Client

Selanjutnya kita akan membuat child parent untuk $p c$ client jadi kita akan memberi nama Total Upload lalu untuk perent wlan1. Setelah itu kita mengatur Maxlimit : kecepatan maksimum yang didapat client kita menggunakan 2M. lalu tekan OK. 


\section{KESIMPULAN DAN SARAN}

\subsection{Kesimpulan}

Dari hasil dan pembahasan di atas dapat disimpulkan dengan adanya pembatasan bandwith membuat kondisi internet pada sebuah perusahaan dapat terjaga dan lebih stabil karena adanya pembatasan bandwith bagi setiap user yang menggunakan internet tersebut.

Dengan adanya sistem pengatur bandwith yang diterapkan, yaitu dengan cara menggunakan mikrotik, dan menggunakan metode Simple Queue dan Queue Tree sehingga informasi dan data yang diperlukan benar tepat dan akurat serta jaringan lebih stabil.

\subsection{Saran}

Untuk memaksimalkan bandwidth yang ada, alangkah baiknya user atau pengguna untuk menggunakan internet sesuai dengan yang diperlukan dan dengan adanya internet berskala kecil yang menggunakan metode manajemen bandwidth Queue Tree ataupun Simple Queue, pengguna dapat menggunakan jaringan dengan stabil dan tidak mengganggu koneksi taransfer bandwidth.

\section{DAFTAR PUSTAKA}

[1] Abdullah, Tamam Asrori, and Misdiyanto, "Optimalisasi Bandwidth Dengan Filterisasi Menggunakan Mikrotik Routerboard di Universitas Panca Marga Probolinggo", Jurnal Energy, No.2, Vol.4, pp. 36-46, 2014. Tersedia pada: https://ejournal.upm.ac.id/index.php/ energy/article/view/614/608

[2]Madcoms, Sistem Jaringan Komputer, Yogyakarta: Penerbit ANDI, 2009.

[3]Rendra Towidjojo, Teori dan Implementasi Menggunakan Router Mikrotik, Jakarta: Jasakom, 2012.

[4] Afdhal Afdhal, Taufiq A., Gani, and Haimi Ardiansyah, "Pengaturan Pemakaian Bandwidth Menggunakan Mikrotik Bridge”, Jurnal Rekayasa Elektrika, No. 2, Vol. 9, pp. 69-76, 2010. Tersedia pada: http://jurnal.unsyiah.ac.id/JRE/article/view/177/170

[5]Rendra Towidjojo, Mikrotik Kung Fu: Kitab 3 Manajemen Bandwidth, Jakarta: Jasakom, 2014.

[6] Eko Agus Darmadi, "Manajemen Bandwidth Internet Menggunakan Mikrotik Router di Polteknik Tri Mitra Karya Mandiri”, Jurnal IKRA-ITH TEKNOLOGI, No. 3, Vol. 3, pp. 8-9, 2019. Tersedia pada: https://journals.upi-yai.ac.id/index.php/ikraithteknologi/article/view/512/381

[7] Moch. Linto Herlambang, Membangun Sharing Koneksi Internet di Windows, Mikrotik, Linux, dan OpenBSD, Yogyakarta: Penerbit ANDI, 2009.

[8]Santoso Setiawan and Mirza Maulana, "Penggunaan Metode Simple Queue dalam Manajemen Bandwidth", Jurnal Teknologi Informatika dan Komputer, No. 2, Vol. 4, pp. 60-61, 2018. Tersedia pada: http://journal.thamrin.ac.id/index.php/jtik/article/viewFile/264/213. 